\title{
On the reconstruction of NiMo electrocatalysts by operando spectroscopy
}

Received 00th January 20xx, Accepted 00th January 20xx DOI: $10.1039 / \times 0 \times x 00000 x$

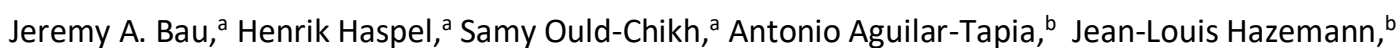
Hicham Idriss, ${ }^{c}$ Kazuhiro Takanabe ${ }^{a, d *}$
Operando spectroscopy is critical for the understanding of electrocatalytic reactions. The structural dynamics of NiMo, one of the most active non-precious catalysts for $\mathrm{H}_{2}$ evolution reaction (HER) in alkaline conditions, were studied by X-ray absorption spectroscopy (XAS) and Raman spectroscopy. We observed considerable unexpected results, some of which may change the way we look at data interpretation. During the operando HER conditions under XAS or visible-light laser irradiation, trace amounts of Mo ions were liberated and then redeposited on the electrodes as a $\mathrm{Mo}^{4+}$-containing oxide, giving the appearance that the HER-active catalyst is in the oxide phase. The Mo oxide selfpropagated under sufficiently energetic light, resulting in a pattern matching the irradiated catalyst area. Detailed spectroscopic characterization of the role of Mo in NiMo may be hindered under operando conditions and care needs to be taken to avoid misleading data interpretation.

\section{Introduction}

In the search for renewable energy vectors, significant attention has been drawn to the generation of $\mathrm{H}_{2}$ gas through water splitting. ${ }^{1-3}$ Electrocatalytic $\mathrm{H}_{2}$ evolution (HER) is best understood on noble metal catalysts that are impractical for scale-up due to supply constraints. To develop new catalysts with earth-abundant elements for the HER and relevant electrocatalytic reactions, operando spectroscopic measurements are critical for understanding active sites and reaction mechanisms on candidate materials because the

\footnotetext{
a. King Abdullah University of Science and Technology (KAUST), KAUST Catalysis Center, Thuwal 23955-6900, Saudi Arabia.

b. Institut Néel, UPR2940 CNRS, University of Grenoble Alpes, F-38000 Grenoble, France.

c. Centre for Research and Development, Saudi Arabian Basic Industries Corporation, KAUST, Saudi Arabia.

d. Department of Chemical Systems Engineering, School of Engineering, The University of Tokyo, 7-3-1 Hongo, Bunkyo-ku, 113-8656, Japan.

${ }^{+}$Electronic Supplementary Information (ESI) available: [Experimental, schema for operando experiments, Supplementary XAS spectra, SEM and AFM images]. See DOI: $10.1039 / x 0 x \times 00000 x$
}

catalysts are often dynamic under reaction conditions. For example, Mo-based catalysts, particularly $\mathrm{NiMo}^{4,5}$ represent the best non-noble HER catalysts discovered to date in alkaline conditions. However, Mo stability and dissolution is a common concern, particularly under alkaline conditions that are most realistic for scale-up. While dissolved Mo has been claimed to be associated with improved catalyst activity, ${ }^{9}$ its fate in solution is poorly understood.

Dissolved ionic species in other electrocatalytic systems can result in unexpected catalytic activation through unintended deposition on electrodes. For example, trace amounts of dissolved $\mathrm{Fe}^{3+}$ are anodically deposited on $\mathrm{Ni}$ oxide during the $\mathrm{O}_{2}$ evolution reaction (OER), resulting in improved catalytic activity. ${ }^{10-12}$ Similarly, Co-based OER catalysts dissolve and redeposit under operando conditions, conferring long-term stability through self-healing mechanisms. ${ }^{13}$ In the case of Co HER catalysts, decomposition of precursor catalysts to metallic Co has been widely demonstrated as the true source of HER activity. ${ }^{14-16}$ Electrocatalyst reconstruction can also have negative effects that undermine long-term stability. For example, Cu metal structures are known to undergo dissolution and re-deposition during $\mathrm{CO}_{2}$ reduction, leading to activity loss. ${ }^{17-20}$ Therefore, understanding and controlling such electrochemical phenomena are of both fundamental and practical interest as they provide crucial insights into catalytic mechanisms while determining whether or not a catalyst is truly viable.

In this report, we describe the re-deposition followed by ordered reconstruction of $\mathrm{MoO}_{x}$ from trace concentrations (10 ppm) of Mo formed during operando HER under X-ray absorption spectroscopy and visible-light induced Raman analyses of NiMo catalysts. After initial electrochemical deposition, $\mathrm{MoO}_{x}$ catalyzes its continuing photodeposition as long as there is sufficiently energetic irradiation, reductive potentials, and dissolved Mo ions. While the deposited $\mathrm{MoO}_{x}$ does not appear to have any direct effect on the NiMo catalytic activity, it prevented the collection of spectroscopic measurements relevant to the role of Mo in the HER. 
Furthermore, this phenomenon may provide a methodology for the controlled deposition of $\mathrm{MoO}_{\mathrm{x}}$

\section{Results and discussion}

Operando X-ray absorption spectroscopy (XAS) measurement was conducted on NiMo films (bulk Ni:Mo $=4: 1$ ) during HER in $0.1 \mathrm{M} \mathrm{KOH}$. Fig. 1 compiles the results of Mo K-edge spectra. Even at low HER rates $\left(-2 \mathrm{~mA} \mathrm{~cm}^{-2}\right.$ at overpotential of $\sim 200 \mathrm{mV}$, Fig. $\mathrm{S2}^{+}$), NiMo films exhibited a monotonic increase in baseline of Mo X-ray Absorption Near-Edge spectra (XANES) during successive extended $\mathrm{X}$-ray absorption fine structure (EXAFS) scans over the course of $7 \mathrm{~h}$ without any sign of deactivation (Fig. 1a). The EXAFS spectrum of the catalyst at the end of the 7-h experiment was dominated by Mo-O bonds $(\approx 2.0 \AA$ ) and lacked the second-shell Mo-Mo bonds typically seen in ordered Mo oxides, indicating an amorphous oxide (Fig. 1b,c). ${ }^{21-25}$ The position of the main edge and the lack of a strong pre-edge structure suggest that the oxidation state of Mo in the catalytically active catalyst was close to $\mathrm{Mo}^{4+}$ with an octahedral symmetry, ${ }^{23-25}$ counter-intuitively implying that Mo oxidized under cathodic HER-active potentials. In contrast, the freshly deposited alloy exclusively presented a first shell at $\sim 2.5 \AA$ in both the $\mathrm{Mo}$ and $\mathrm{Ni} \mathrm{K}$-edges corresponding to metal-metal bonds (Fig. 1C, Fig. $\mathrm{S}^{\dagger}{ }^{\dagger}$ ). Unlike Mo, the Ni signal showed no substantial changes during the acquisition of XAS. Under oxidizing potentials ( $+0.3 \mathrm{~V}$ vs. RHE), the Mo baseline gradually decreased, resulting in the near-restoration of the metallic near-edge structure of the original catalyst over the course of 4 h (Fig. 1d, Fig. $\mathrm{S}^{\dagger}{ }^{\dagger}$ ). Although these results appeared to contradictorily suggest that Mo oxidation was taking place during reduction (and vice versa), the gradually rising baseline in the Mo spectra implied that the findings were a result of deposition, not oxidation. Confirming this theory, unidimensional scans of the electrode with the synchrotron beam revealed beam-dependent growth of $\mathrm{MoO}_{x}$ at the conclusion of XAS experiments, whereas surrounding regions did not grow at all (spot size $100 \mu \mathrm{m}$ by $220 \mu \mathrm{m}$, Fig. 1e). The height of the growth roughly corresponded to the change in the edge jump during XAS, and the amount of Mo in the spot was 2-4 times greater than the amount of Mo in the surrounding film. Growth was also observed in $\mathrm{MoO}_{\mathrm{x}}$ films, demonstrating that the behavior was specific to Mo and took place regardless of the presence of $\mathrm{Ni}$ (Fig. 1f).

$\mathrm{MoO}_{\mathrm{x}}$ growth and reconstruction on NiMo was also observed in operando Raman spectroscopy, demonstrating that the behavior observed in XAS was not an effect related to the interaction of the high flux of X-rays and the electrocatalytic system. With irradiation of a $2-\mathrm{mW}$ laser $(\lambda=473 \mathrm{~nm}$, spot size $\left.1 \mu^{2}\right)$, the Raman spectrum of a NiMo electrode was composed of three broad peaks at 270,500 , and $700 \mathrm{~cm}^{-1}$, and one sharp peak at $1000 \mathrm{~cm}^{-1}$ at HER ( $-50 \mathrm{mV}$ vs. RHE) in $0.1 \mathrm{M}$ $\mathrm{KOH}$ (Fig. 2a). Changes in the Raman spectrum were commensurate with the appearance of visible spots reflecting the laser illumination size (inset). The sharp peak at $\sim 270 \mathrm{~cm}^{-1}$ corresponded to the stretching mode of terminal $\mathrm{Mo}^{6+}=0,26$ whereas the broad peaks at $400-800 \mathrm{~cm}^{-1}$ were merged forms of major crystalline $\mathrm{MoO}_{2}$ Raman peaks ${ }^{27,28}$ consistent with the electrodeposited amorphous $\mathrm{MoO}_{x}{ }^{29}$ This result confirms that the deposit is in a $\mathrm{Mo}^{4+}$-containing $\mathrm{MoO}_{2}$-like amorphous structure. The operando measurements also revealed that the HER performance was not influenced by this $\mathrm{MoO}_{x}$ deposition. Since deposition only affects regions under spot irradiation as opposed to the entire electrode, the effects of the $\mathrm{MoO}_{\mathrm{x}}$ on the HER itself are difficult to determine. However, based on the physical similarities with the previously reported material (which was found to be permeable to water), ${ }^{29}$ the oxide most likely has no direct effect on the HER. (a)

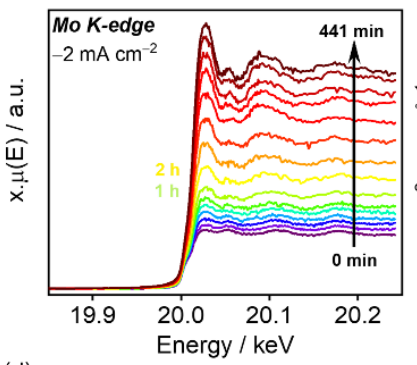

(d)

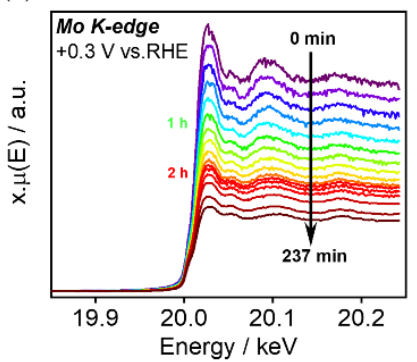

(b)

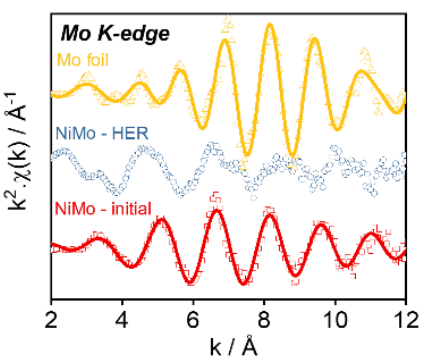

(e)

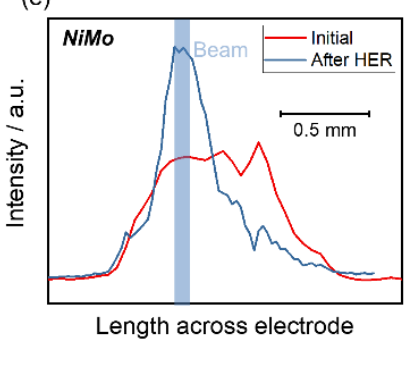

(c)

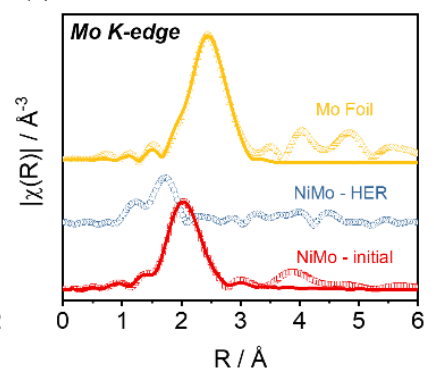

(f)

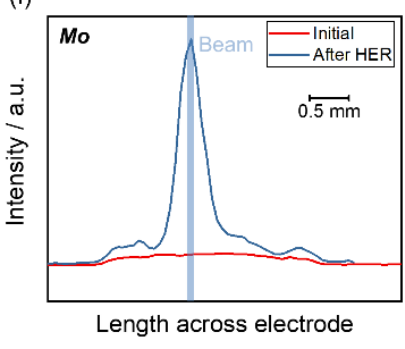

Fig. 1. (a) Operando XANES of Mo K-edge of NiMo at $-2 \mathrm{~mA} \mathrm{~cm}^{-2}$. (b) EXAFS and (c) Fourier transforms of Mo K-edge for NiMo catalyst before (initial) and during HER compared with a spectrum for Mo metal foil. (d) Operando XANES of Mo K-edge of NiMo at $0.3 \mathrm{~V}$ vs. RHE after HER in $0.1 \mathrm{M} \mathrm{KOH}$. Mo K-edge line scans of (e) NiMo and (f) Mo (in the absence of Ni) before and after HER experiments $\left(-2 \mathrm{~mA} \mathrm{~cm}^{-2}\right)$. 
(a)

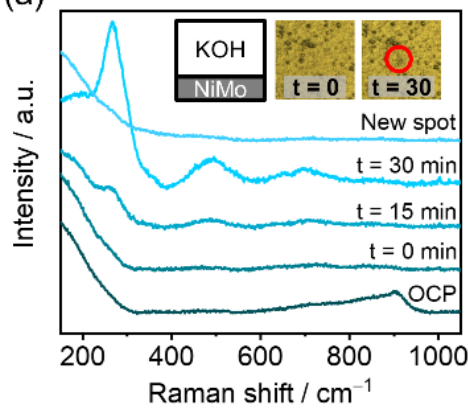

(d)

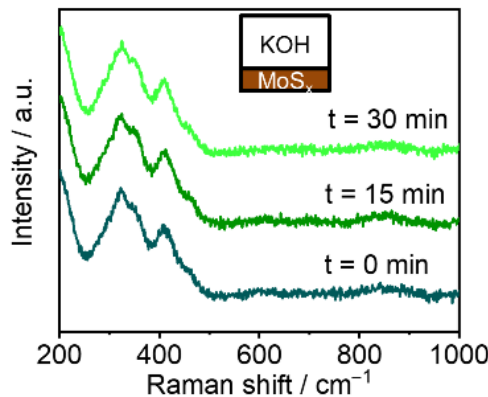

(b)

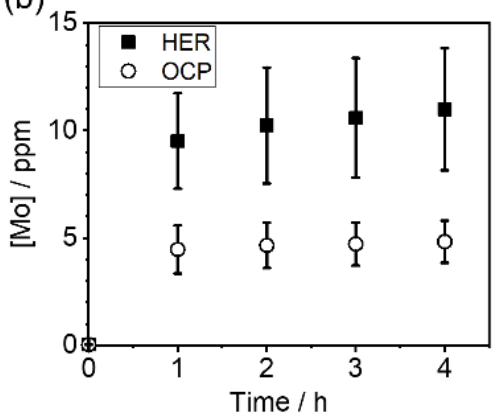

(e)

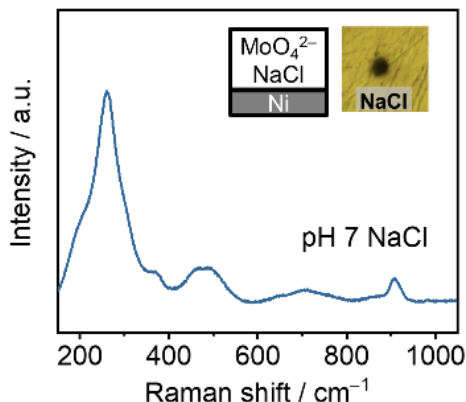

(c)

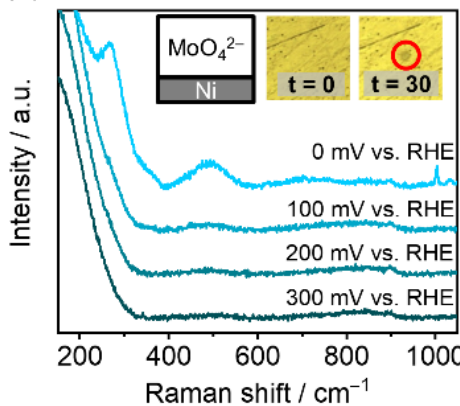

(f)

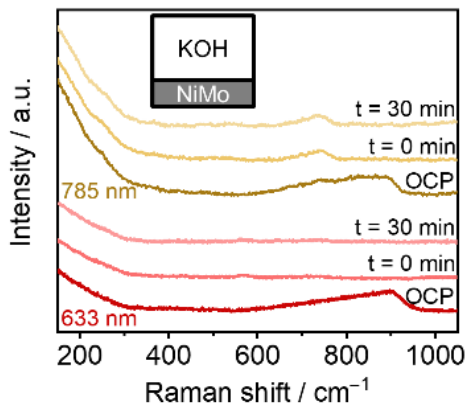

Fig. 2. (a) Operando Raman spectra of NiMo catalysts at OCP and O V vs. RHE during irradiation with 2-mW/spot $473-\mathrm{nm}$ laser in $0.1 \mathrm{M}$ KOH. (b) Concentration of dissolved Mo determined by ICP-MS of NiMo films in small volumes $(5 \mathrm{~mL})$ of $0.1 \mathrm{M} \mathrm{KOH}$ under HER $\left(-2 \mathrm{~mA} \mathrm{~cm} \mathrm{~cm}^{-2}\right)$ and open circuit potential (OCP) conditions. Error bars achieved by repeating experiments four times. (c) Raman spectra collected using 2-mW/spot 473-nm laser at different potentials in $1 \mathrm{mM} \mathrm{Na} \mathrm{MoO}_{4} / 0.1 \mathrm{M} \mathrm{KOH}$ on Ni electrode. (d) Operando Raman spectra of cathodically electrodeposited MoS films collected using 2-mW/spot 473-nm laser at $0 \mathrm{~V}$ vs. RHE in $0.1 \mathrm{M} \mathrm{KOH}$. (e) Operando Raman spectra collected using 2-mW/spot 473-nm laser at $0 \mathrm{~V}$ vs. RHE in $1 \mathrm{mM} \mathrm{Na} \mathrm{MoO}_{4} / 0.5 \mathrm{M} \mathrm{NaCl}$ (pH 7) on Ni. (f) Operando Raman spectra of NiMo catalyst at OCP and 0 V vs. RHE during irradiation with 2-mW/spot 633 and 785-nm lasers in $0.1 \mathrm{M} \mathrm{KOH}$. Inset images in (a) and (c) depict the irradiated area before and after 30 min irradiation. Inset image in (e) was the result of 30 min irradiation.

Formation and stability of $\mathrm{MoO}_{\mathrm{x}}$ in highly alkaline conditions are not predicted by the electrochemical equilibrium of Mo in aqueous solutions, ${ }^{30,31}$ but indeed non negligible amounts of dissolved Mo ( 10 ppm, $0.1 \mathrm{mM}$ ) were detected in the electrolyte upon cathodic application compared to NiMo catalyst left at open circuit potential (OCP) (Fig. 2b). Nonetheless, deposition can be repeated on a Mo-free electrode in an electrolyte with trace Mo using otherwise similar conditions $\left(0.1 \mathrm{M} \mathrm{KOH} / 1 \mathrm{mM} \mathrm{Na} 2 \mathrm{MoO}_{4}\right.$, potentials at and more cathodic than $0 \mathrm{~V}$ vs. RHE) (Fig 2c). According to both the Pourbaix diagram for Mo and prior knowledge of Mo oxides in aqueous conditions, Mo undergoes a series of redox events $(3+/ 6+, 3+/ 4+, 4+/ 6+)$ near $0 \mathrm{~V}$ vs. RHE. ${ }^{30-32}$ Since $\mathrm{Na}_{2} \mathrm{MoO}_{4}$ solutions do not absorb visible light (Fig. 3a), we propose that a layer of $\mathrm{MoO}_{\mathrm{x}}$ is first electrodeposited onto the electrode surface, which in turn propagates in the presence of both light and cathodic potential. The photodeposition effect did not take place with amorphous $\operatorname{MoS}_{x}$, another Mo-based HER catalyst with good HER activity and stability particularly in acidic condition (Fig. 2d). ${ }^{6}$ Deposition also took place at less caustic conditions $(\mathrm{pH} 7,0.5 \mathrm{M} \mathrm{NaCl})$, making this phenomenon amenable for depositing $\mathrm{MoO}_{x}$ features (Fig. 2e).
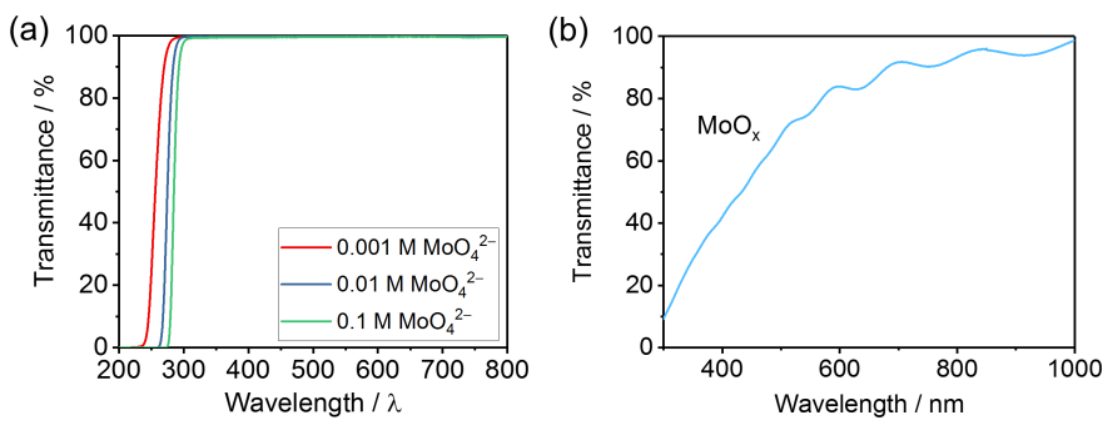

(c)

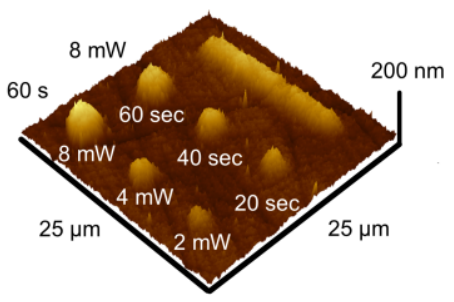

Fig. 3. (a) UV-vis spectra of different concentrations of $\mathrm{Na}_{2} \mathrm{MoO}_{4}$ solutions, (b) UV-vis spectrum of $\mathrm{MoO}_{x}$ film deposited on FTO at $-0.4 \mathrm{~V}$ vs. RHE and $300 \mathrm{~W}$ of Xe irradiation, normalized to the UV-vis spectrum of blank FTO. (c) AFM profile of $\mathrm{MoO}_{x}$ photolithographic patterns. Effects of irradiation power for $1 \mathrm{~min}(8,4,2 \mathrm{~mW}$, left to right, bottom left row) and varying irradiation time at $8 \mathrm{~mW}(60,40,20 \mathrm{~s}$, left to right, middle row). 
In contrast to the behavior under $473 \mathrm{~nm}$ laser irradiation, NiMo electrodes irradiated at higher wavelengths $(\lambda=633,785$ $\mathrm{nm}$ ) did not exhibit $\mathrm{MoO}_{\mathrm{x}}$ growth (Fig. 2f), suggesting that photoexcitation is bandgap-like origin. To examine the optical properties of $\mathrm{MoO}_{x}$, large surface area $\mathrm{MoO}_{x}$ films were deposited on transparent fluorine-doped tin oxide (FTO) electrodes from $0.1 \mathrm{M} \mathrm{KOH} / 0.1 \mathrm{M} \mathrm{Na}_{2} \mathrm{MoO}_{4}$ using a 300-W Xe lamp and a cold mirror $(\lambda<450 \mathrm{~nm})$ at $-0.4 \mathrm{~V}$ vs. RHE. The broad absorption of the $\mathrm{MoO}_{\mathrm{x}}$ films in a wide range of visible light is consistent with the previously determined absorption characteristics for semiconducting $\mathrm{MoO}_{2}$, with a bandgap close to $2.5 \mathrm{eV}$ (corresponding to a wavelength $\sim 500 \mathrm{~nm}$ ) that explains the ability of $\mathrm{MoO}_{x}$ to absorb $473 \mathrm{~nm}$ but not $633 \mathrm{~nm}$ irradiation (Fig. 3b). ${ }^{33,34} \mathrm{~A}$ weak but non-negligible photoresponse was detected by such $\mathrm{MoO}_{\mathrm{x}}$ films under illumination (Fig. $\mathrm{S}^{+}$). The successful deposition on FTO has thus confirmed that the substrate nature had no effect on the deposition phenomenon. A thermal cause for deposition was excluded due to the lack of $\mathrm{MoO}_{\mathrm{x}}$ growth under infrared light $(785 \mathrm{~nm})$, as well as the increased $\mathrm{MoO}_{x}$ dissolution at higher temperatures. ${ }^{35}$

Based on the behavior of $\mathrm{MoO}_{x}$ films arising from dissolved Mo, we propose the following mechanism of $\mathrm{MoO}_{x}$ deposition on NiMo and subsequent behavior under irradiation (Scheme 1). Initially, under cathodic potentials, hydroxides are generated. Subsequently, a small fraction of Mo dissolves into the electrolyte solution (as $\mathrm{Mo}^{6+}$ ), due to local increases in $\mathrm{pH}$. Finally, $\mathrm{Mo}^{6+}$ is redeposited on the surface of the NiMo as an initial layer of $\mathrm{MoO}_{\mathrm{x}}$ that grows upon further absorption of radiation of sufficient energy, resulting in the reduction of dissolved $\mathrm{Mo}^{6+}$ to a $\mathrm{Mo}^{4+}$-containing oxide by excited electrons transferred from the $\mathrm{CB}$ of $\mathrm{MoO}_{2}$. Meanwhile, dissolution gradually takes place under OCP due to the high $\mathrm{pH}$, but is accelerated at $0.3 \mathrm{~V}$ vs. RHE due to the application of anodic current. Using these simple steps, we provide a proof-ofconcept technique for depositing $\mathrm{MoO}_{x}$ nanostructures using a confocal Raman setup in $1 \mathrm{mM} \mathrm{Na} \mathrm{MoO}_{4} / 0.5 \mathrm{M} \mathrm{NaCl}$ at $0 \mathrm{~V}$ vs. RHE with a 473-nm laser (Fig. 3c). Modulating the intensity of the incident laser on the substrate $(2-8 \mathrm{~mW})$ and the exposure time $(20-60 \mathrm{~s})$ yielded features with thicknesses of $50-150 \mathrm{~nm}$ (Figs. S6, $\mathrm{S7}^{+}$). Furthermore, more complicated patterns such as lines can be prepared by repeated scanning (Fig. 3c). This wellcontrolled deposition technique may be applicable to advanced electrode and photoelectrode fabrication for active and durable HER performance.

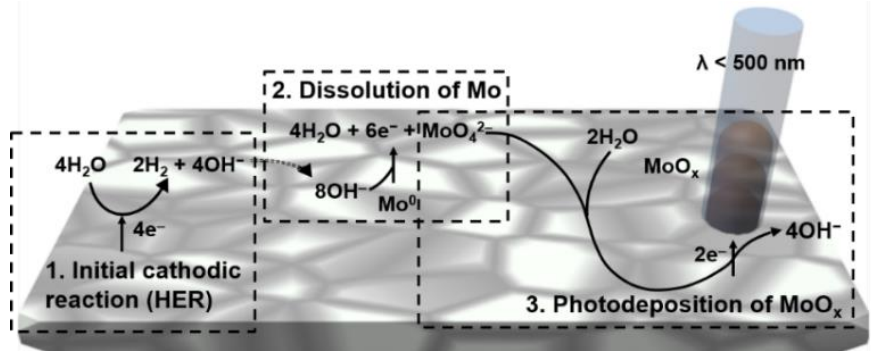

Scheme 1. Proposed mechanism of Mo dissolution and re-deposition under irradiation on NiMo electrocatalyst electrodes.

\section{Conclusions}

Photon-induced deposition of amorphous $\mathrm{MoO}_{\mathrm{x}}$ from dissolved Mo cations in operando study of NiMo HER has been observed. This deposition did not affect the HER activity but altered the Mo-K edge spectra significantly in a manner that may induce erroneous conclusions related to redox reactions. The ability of the photoelectrochemical reaction to counter the alkaline dissolution of Mo ions is also potentially useful for depositing conformal $\mathrm{MoO}_{\mathrm{x}}$ patterns without the need for an overly complicated setup. A multiple-step mechanism involving dissolution, deposition and light stimulated growth of $\mathrm{MoO}_{\mathrm{x}}(\mathrm{x}$ 2) was proposed. Ultimately, NiMo remains the topperforming non-precious alkaline HER catalyst, but the reconstruction of Mo limits potential characterization approaches.

\section{Conflicts of interest}

There are no conflicts to declare.

\section{Acknowledgements}

The research reported in this study was supported by the King Abdullah University of Science and Technology. The authors acknowledge the support of SABIC in funding this research. The FAME-UHD project is financially supported by the French large loan EquipEx (EcoX, ANR-10-EQPX-27-01), the CEA-CNRS CRG consortium and the INSU CNRS Institute.

\section{Notes and references}

1 J. H. Montoya, L. C. Seitz, P. Chakthranont, A. Vojvodic, T. F. Jaramillo, J. K. Nørskov, Nat. Mater. 2017, 16, 70-81.

2 M. Zeng, Y. Li, J. Mater. Chem. A, 2015, 3, 14942.

3 X. Li, X. Hao, A. Abudula, G. Guan, J. Mater. Chem. A, 2016, 4, 11973.

4 J. Zhang, T. Wang, P. Liu, Z. Liao, S. Liu, X. Zhuang, M. Chen, E. Zschech, X. Feng, Nat. Commun. 2017, 8, 15437.

5 P. M. Csernica, J. R. McKone, C. R. Mulzer, W. R. Dichtel, H. D. Abruña, F. J. DiSalvo, ACS Catal., 2017, 7, 3375.

6 P. D. Tran, T. V. Tran, M. Orio, S. Torelli, Q. D. Truong, K. Nayuki, Y. Sasaki, S. Y. Chiam, R. Yi, I. Honma, et al., Nat. Mater. 2016, 15, 640-646.

7 Y. Ouyang, Q. Li, L. Shi, C. Ling, J. Wang, J. Mater. Chem. A 2018, 6, 2289.

8 I. Roger, R. Moca, H. N. Miras, K. G. Crawford, D. A. J. Moran, A. Y. Ganin, M. D. Symes, J. Mater. Chem. A, 2017, 5, 1472.

9 C. Lupi, A. Dell'Era, M. Pasquali, Int. J. Hydrogen Energy 2014, 39, 1932.

10 L. Trotochaud, S. L. Young, J. K. Ranney, S. W. Boettcher, J. Am. Chem. Soc., 2014, 136, 6744.

11 M. P. Browne, S. Stafford, M. O'Brien, H. Nolan, N. C. Berner, G. S. Duesberg, P. E. Colavita, M. E. G. Lyons, J. Mater. Chem. A, 2016, 4, 11397.

12 Y. Kuang, Q. Jia, G. Ma, T. Hisatomi, T. Minegishi, H. Nishiyama, M. Nakabayashi, N. Shibata, T. Yamada, A. Kudo, et al., Nat. Energy, 2017, 2, 16191.

13 D. A. Lutterman, Y. Surendranath, D. G. Nocera, J. Am. Chem. Soc., 2009, 131, 3838. 
14 N. Kaeffer, A. Morozan, J. Fize, E. Martinez, L. Guetaz, V. Artero, ACS Catal., 2016, 6, 3727.

15 B. Lassalle-Kaiser, D. Merki, H. Vrubel, S. Gul, V. K. Yachandra, X. Hu, J. Yano, J. Am. Chem. Soc., 2015, 137, 314.

16 Y. Zhu, H.-C. Chen, C.-S. Hsu, T.-S. Lin, C.-J. Chang, S.-C. Chang, L.-D. Tsai, H. M. Chen, ACS Energy Lett., 2019, 4, 987.

17 J. Huang, N. Hörmann, E. Oveisi, A. Loiudice, G. L. D. Gregorio, O. Andreussi, N. Marzari, R. Buonsanti, Nat. Commun. 2018, 9, 3117.

18 P. D. Luna, R. Quintero-Bermudez, C.-T. Dinh, M. B. Ross, O. S. Bushuyev, P. Todorović, T. Regier, S. O. Kelley, P. Yang, E. H. Sargent, Nat. Catal., 2018, 1, 103.

19 J. He, A. Huang, N. J. J. Johnson, K. E. Dettelbach, D. M. Weekes, Y. Cao, C. P. Berlinguette, Inorg. Chem. 2018, 57, 14624.

20 Z. Weng, X. Zhang, Y. Wu, S. Huo, J. Jiang, W. Liu, G. He, Y. Liang, H. Wang, Angew. Chem. Int. Ed. 2017, 56, 13135.

$21 \mathrm{H}$. Shimada, N. Matsubayashi, T. Sato, Y. Yoshimura, A. Nishijima, N. Kosugi, H. Kuroda, J. Catal., 1992, 138, 746.

22 O. Hirsch, G. Zeng, L. Luo, M. Staniuk, P. M. Abdala, W. van Beek, F. Rechberger, M. J. Süess, M. Niederberger, D. Koziej, Chem. Mater. 2014, 26, 4505.

23 T. Ressler, O. Timpe, T. Neisius, J. Find, G. Mestl, M. Dieterle, R. Schlögl, J. Catal. 2000, 191, 75.

24 T. Ressler, J. Wienold, R. E. Jentoft, T. Neisius, J. Catal. 2002, 210, 67.

25 Y. Zhou, H. Xie, C. Wang, Q. He, Q. Liu, Z. Muhammad, Y. A. Haleem, Y. Sang, S. Chen, L. Song, J. Phys. Chem. C 2017, 121 15589.

26 W. Liu, Q. Xu, W. Cui, C. Zhu, Y. Qi, Angew. Chem. Int. Ed. 2017, 56,1600

27 Y. Jin, P. K. Shen, J. Mater. Chem. A, 2015, 3, 20080.

28 X. Xia, S. Deng, D. Xie, Y. Wang, S. Feng, J. Wu, J. Tu, J. Mater. Chem. A, 2018, 6, 15546.

29 A. T. Garcia-Esparza, T. Shinagawa, S. Ould-Chikh, M. Qureshi, X. Peng, N. Wei, D. H. Anjum, A. Clo, T.-C. Weng, D. Nordlund, et al. Angew. Chem. Int. Ed. 2017, 56, 5780.

30 V. S. Saji, C.-W. Lee, ChemSusChem, 2012, 5, 1146.

31 M. Pourbaix, Atlas of Electrochemical Equilibria in Aqueous Solutions; Pergamon Press: New York, 1966.

32 K. Machida, M. Enyo, J. Electrochem. Soc. 1990, 137, 1169.

33 K. Inzani, M. Nematollahi, F. Vullum-Bruer, T. Grande, T. W. Reenaas, S. M. Selbach, Phys. Chem. Chem. Phys. 2017, 19, 9232.

34 N. Dukštienė, D. Sinkevičiūtė, J Solid State Electrochem., 2013, 17,1175

35 J. B. Lee, Corrosion, 1981, 37, 467-481. 